\title{
CORRELATION BETWEEN BACK MUSCLE STRENGTH AND MOBILITY IN OLDER WOMEN WITH OSTEOPOROSIS
}

Madeline Luiza Ferreira Pivovarsky ${ }^{1, \star}$, Renata Gonçalves Pinheiro Corrêa ${ }^{1}$, Liliana Laura Rossetin ${ }^{1}$, Daniela Gallon Correa ${ }^{1}$, Heloísa Salamoni

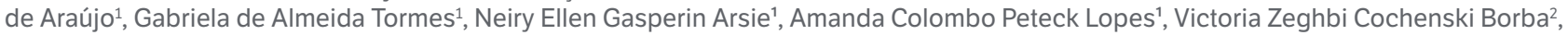
Ana Carolina Brandt de Macedo ${ }^{1}$, Anna Raquel Silveira Gomes ${ }^{1}$

1.Universidade Federal do Paraná, Curitiba (PR), Brazil. 2.Universidade do Paraná, Curitiba (PR), Brazil.

*Corresponding author: madeline8497@gmail.com

\section{BACKGROUND}

Older women with osteoporosis present high levels of physical inactivity, compression fractures, pain and postural deficits, which lead to disfunctions in the trunk. So, it is important to assess the trunk muscle function of this population. The objective of this study is to verify the correlation between mobility, range of motion (ROM), posture and strength of the trunk in women with osteoporosis.

\section{MATERIALS AND METHODS}

This research included older women with osteoporosis over the age of 65. Lumbar mobility was evaluated by Schober's test, hamstring and lower back flexibility (HLBF) by sit and reach test; hamstring flexibility by active-knee extension test; ROM by goniometer; lordosis angle (LA) by flexicurve; trunk flexors and extensors isometric peak of force (IPF) by a hand-held dynamometer. Normality was checked with Shapiro-Wilk test; Pearson or Spearman was used for correlation between variables and linear regression to establish a relationship between dependent and independent variables.

\section{RESULTS}

A sample of 19 women $\left(72.36 \pm 6.19\right.$ years) enrolled the study, with a body mass index of $30.04 \pm 6.50 \mathrm{~kg} / \mathrm{m}^{2}$ - overweight. Lumbar mobility correlates with $L A(r=0.494 ; p=0.044)$ and $\operatorname{HLBF}(r=0.530 ; p=0.024)$, with 4.7 and $25.8 \%$ of interference, respectively. Besides, HLBF is explained in $31.7 \%$ by LA ( $r=0.600 ; p=0.011)$ and in $17.3 \%$, by lumbar flexion ROM ( $r=0.470 ; p=0.049)$. The $L A$ is explained in $26.9 \%$ by hamstring flexibility $(r=-0.675 ; p=0.003)$ and in $21.9 \%$ by lumbar flexion ROM $(r=0.563 ; p=0.019)$. Also, the trunk muscle flexors IPF is explained in $28.5 \%$ by hamstrings flexibility $(r=-0.574 ; p=0.016)$, in $39.0 \%$ by lumbar flexion ROM $(r=0.654 ; p=0.004)$ and in $50.0 \%$ by LA $(r=0.765 ; p=0.001)$. The IPF of trunk muscle extensors is explained in $21.0 \%$ by $\operatorname{HLBF}(r=0.513 ; p=0.042)$, in $60.9 \%$ by the hamstring flexibility $(r=-0.797 ; p=0.000)$ and in $20.4 \%$ by LA $(r=0.559 ; p=0.030)$.

\section{CONCLUSION}

The rehabilitation of this patients should contain interventions aiming to enhance flexibility and strength to ameliorate the postural deficits and to optimize the musculoskeletal function.

\section{ACKNOWLEDEGMENTS}

Universidade Federal do Paraná. Complexo Hospital de Clínicas UFPR. Programa de Pós-graduação em Educação Física da UFPR. Programa de Pós-graduação em Medicina Interna da UFPR. Serviço de Endocrinologia e Metabologia do HC-UFPR. Coordenação de Aperfeiçoamento de Pessoal de Nível Superior - Brasil (CAPES). Conselho Nacional de Desenvolvimento Científico e Tecnológico - CNPq. Sanepar. DSYS LAB. 